\title{
Determinants and pattern of care seeking for preterm newborns in a rural Bangladeshi cohort
}

\author{
Rashed Shah ${ }^{1,2^{*}}$, Luke C Mullany ${ }^{1}$, Gary L Darmstadt ${ }^{3}$, Radwanur Rahman Talukder ${ }^{4}$, Syed Moshfiqur Rahman ${ }^{4}$, \\ Ishtiaq Mannan ${ }^{5}$, Shams El Arifeen ${ }^{4}$, Abdullah H Baqui ${ }^{1,4}$ and on behalf of the ProjAHNMo Study Group in \\ Bangladesh
}

\begin{abstract}
Background: Despite the increased burden of preterm birth and its complications, the dearth of care seeking data for preterm newborns remains a significant knowledge gap. Among preterm babies in rural Bangladesh, we examined: 1) determinants and patterns of care seeking, and 2) risk analysis for care-seeking from qualified and unqualified providers.
\end{abstract}

Method: Trained community health workers collected data prospectively from 27,460 mother-liveborn baby pairs, including 6,090 preterm babies, between June 2007 and September 2009. Statistical analyses included binomial and multinomial logistic regressions.

Results: Only one-fifth (19.7\%) of preterm newborns were taken to seek either preventive or curative health care. Among care-seeker preterm newborns, preferred providers included homeopathic practitioners (50.0\%), and less than a third (30.9\%) sought care from qualified providers. Care-seeking from either unqualified or qualified providers was significantly lower for female preterm babies, compared to male babies [Relative Risk Ratio (RRR) for unqualified care: 0.68; 95\% Confidence Interval (Cl): 0.58, 0.80; RRR for qualified care: 0.52; 95\% Cl: 0.41, 0.66]. Among preterm babies, care-seeking was significantly higher among caregivers who recognized symptoms of illness [RR: 2.14; 95\% Cl: $1.93,2.38$ ] or signs of local infection (RR: $2.53 ; 95 \%$ Cl: $2.23,2.87$ ), had a history of child death [RR: $1.21 ; 95 \%$ Cl: 1.07, 1.37], any antenatal care (ANC) visit [RR: $1.41 ; 95 \%$ Cl: 1.25, 1.59]. Birth preparedness (RRR: 1.24; 95\% Cl: 1.09 , 1.68 ) and any ANC visit (RRR: $1.73 ; 95 \% \mathrm{Cl}: 1.50,2.49)$ were also associated with increased likelihood of care seeking for preterm babies from qualified providers.

Conclusion: To improve care seeking practices for preterm babies and referral of sick newborns to qualified providers/facilities, we recommend: 1) involving community-preferred health care providers in community-based health education and awareness raising programs; 2 ) integrating postnatal care seeking messages into antenatal counselling; and 3) further research on care seeking practices for preterm babies.

\section{Background}

Preterm newborns are at substantially higher risk for morbidity and mortality than full-term infants [1]. The burden of preterm birth and its complications have been increasing [2] and represent a significant issue in combating neonatal health risks and reducing neonatal mortality [3,4],

\footnotetext{
* Correspondence: mshah@savechildren.org

'Department of International Health, International Center for Maternal and Newborn Health (ICMNH), Johns Hopkins Bloomberg School of Public Health, Baltimore, Maryland, USA

2Department of Health and Nutrition, Save the Children-USA, Washington, DC, USA

Full list of author information is available at the end of the article
}

yet there is a paucity of research on care seeking for preterm newborns [5]. A few studies have reported behavioural aspects related to care-seeking practices [6-10], but often lack quantitative information on health care utilization, especially for preterm newborns. A systematic review on care-seeking for neonatal illness in low and middle income countries [5] unveiled a wide pattern for neonatal care seeking across study populations. In Bangladesh, studies have demonstrated that the proportion of newborns for whom care was sought from qualified providers (defined as doctors, nurse and paramedics trained to clinically practice western medicine) 
can vary substantially but generally is low (e.g. from $17 \%$ to $34 \%$ ) [11-13].

Given the variability of socio-demographic and cultural contexts, differentials in perception of vulnerability or risk for newborns, and prevailing customs, traditions and beliefs within communities, it is critically important to understand community-specific patterns and determinants of population-level neonatal care seeking practices, especially for preterm newborns. Such data could help identify gaps and inform program approaches to promote care seeking for preterm babies [5,14].

We aimed to examine the patterns and determinants of care seeking for preterm newborns and to conduct comparative risk analysis for care-seeking from qualified and unqualified providers of health care in a rural community in Bangladesh. As a complex interaction of multiple factors can cause delay in the decision to seek care [15-17], our approach is clarified through an adaptation of Andersen's socio-behavioural model [18] of health services (Figure 1). We incorporated both 1) predisposing [maternal age, parental educational level, sex of the baby, previous obstetric history, birth order, antenatal care (ANC) status] and 2) enabling factors (socio-economic status, distance from a health facility) in the model, and assumed that an individual's choice to seek health care is guided by these two types of factors. Other 'need' factors (e.g. recognition and perception of the need and severity) act as triggers on the decision which drive the individual to either seek care or refrain from seeking care [19] and are also included as independent variables in our analyses. Care-seeking for newborns, especially for preterm newborns, was additionally characterized by place of health care-seeking (home vs. facility). Finally, given the cultural norm of confinement or seclusion of both mother and baby until 40 days postpartum [20] in our area (and more broadly throughout South Asia), we also examined the care-seeking pattern from qualified vs. unqualified providers.

\section{Methods}

\section{Study design}

We analyzed prospectively collected data from a large community-based cluster-randomized trial (registered at ClinicalTrials.gov \# NCT00434408) conducted in Sylhet district of Bangladesh to evaluate the impact of single or multiple (i.e. daily) cleansing of the umbilical cord with $4.0 \%$ chlorhexidine solution on overall neonatal mortality and incidence of cord infections. Details of the trial design have been published elsewhere [21].

\section{Study setting, population and implementation}

The study was implemented in 22 unions (the smallest administrative unit with a health center) of Sylhet district in north-eastern Bangladesh during June 2007- September 2009. One female community health worker (CHW) was assigned for implementation of interventions and data collection from study participants in each of 133 geographical working units ("clusters") within the study area.

Health care was available to the community within the study area through first-level health centers (each serving 20,000 population) and sub-district hospitals (each for $\sim 200,000$ population), neither of which were equipped

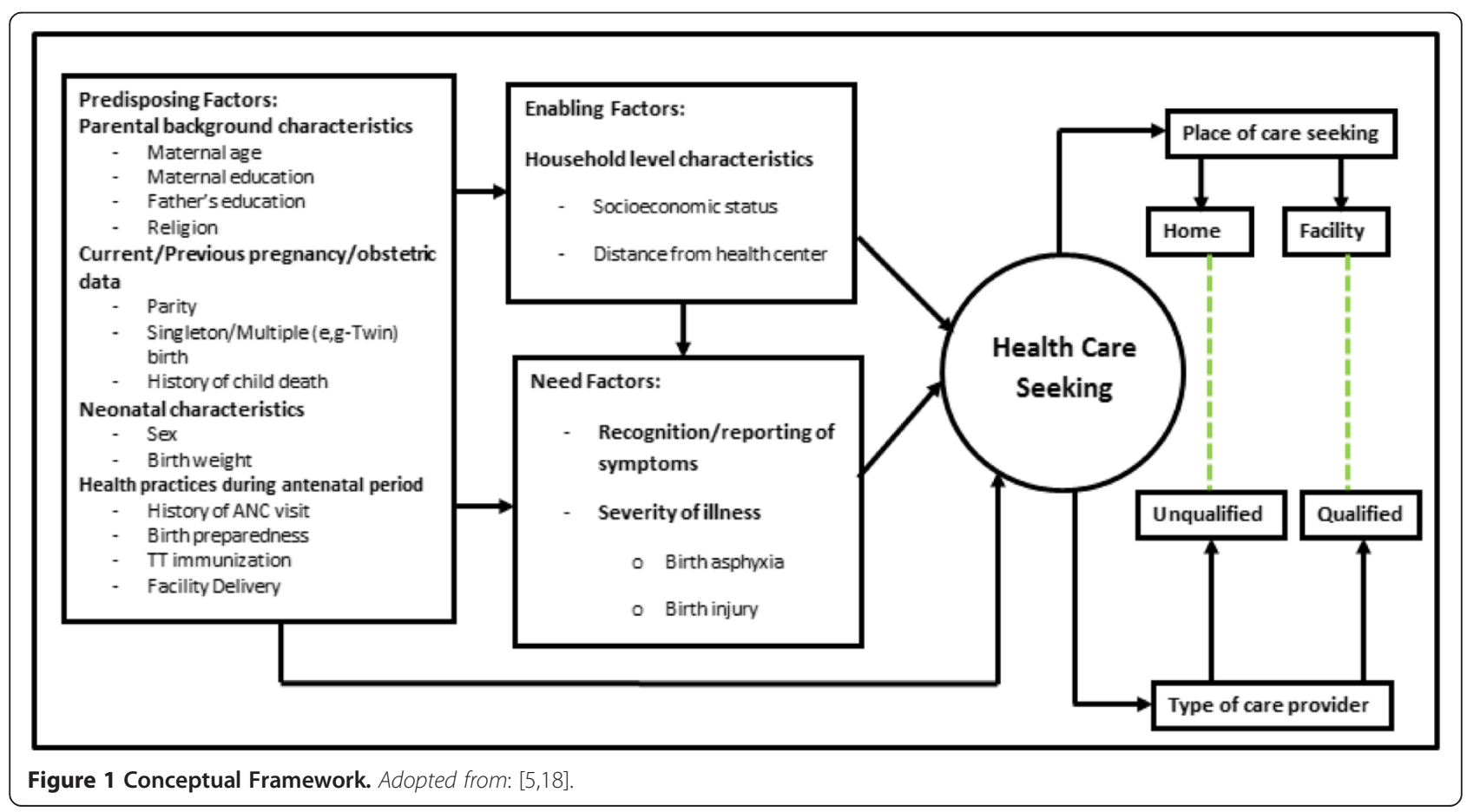


to provide emergency care to newborns, especially preterm babies. Sylhet Medical College Hospital offered such specialized care but its location outside the study area requires approximately 2.5 hours to reach by bus.

\section{Study implementation}

Bi-monthly pregnancy surveillance was conducted among all married women of reproductive age by house-to-house visits. Newly identified pregnant women were enrolled in the study, following agreement through an oral informed consent procedure. CHWs delivered a package of maternal and newborn health interventions (Additional file 1) and collected relevant data from all enrolled women at scheduled antenatal home visits (scheduled at $\sim 12-16$ and $\sim 32$ weeks gestational age). Enrolled women were followed through the end of pregnancy, and CHWs made scheduled visits at home during the postnatal period (days $0,2,5,14$, and 27) to assess the newborn using standardized tools.

\section{Assessment of independent variables}

At enrollment, data were collected on age, literacy, religion, pregnancy history, and socio-demographic and economic information (educational attainment of women and husbands, household construction materials and assets). CHWs collected information on maternal care-seeking practices during antenatal home visits. They also assessed the family's birth and newborn care preparedness (BNCP) status, reflected by practice of the following steps: selection of 1) a birth attendant and 2) newborn care personnel; arrangement for 3) clothes for newborn drying/wrapping, and 4) emergency transport, if needed; 5) allocating emergency savings; and 6) possession of a clean delivery kit (CDK). BNCP status was categorized as "fully compliant" (all 6 of the above-mentioned steps were reported as practiced), "partially compliant" (practiced 1-5 steps), or "non-compliant" (0 steps taken).

At the first postnatal home visit, CHWs collected basic data on labor and delivery, date/time of birth, and sex of the baby. At all postnatal visits, additional data on immediate essential newborn care practices (bathing, drying, wrapping, breastfeeding), reported morbidity, and vital status of the child were collected.

\section{Primary exposure variable}

LMP date was recorded at the enrollment visit and maternal recall was facilitated by using calendars and memory aids. Some women could not remember/report their LMP date and some women became pregnant during the postpartum amenorrheic period and thus could not provide an LMP date. For those with available LMP estimate, gestational age at birth (in completed weeks) was computed by subtracting the reported date of the first day of the last menstrual period (LMP) from the date of birth.

\section{Assessment of outcome variable}

The primary outcome in this study was "care seeking". Care seeking was defined as any care (either preventive or curative) sought from any health care provider (either qualified or non-qualified) for a newborn. Relevant operational definitions and health care provider categories are listed in Additional file 2.

\section{Statistical analyses}

Our analyses included all reported live births within the study area during the study period who received a CHW's assessment visit during the first two weeks of life. We excluded women who, at the time of enrollment, could report neither an LMP date nor the duration (in month/day) since her last menstruation, as this estimate was required to define gestational age for each live-born baby.

The broad 'care seeking' variable was further categorized as: 1) sought no care, and those who sought care from 2) unqualified providers, or 3) qualified providers. We treated these categories following the above mentioned hierarchical order and the highest category was considered in case of seeking care from multiple categories of health care providers (for example if a baby sought care from unqualified providers on the first attempt and later sought care from a qualified provider, this baby was counted as a care seeker from a qualified provider).

Preterm was identified as birth before 37 completed weeks of gestation, or fewer than 259 days since the first day of the LMP [22]. Adapted from previous studies and existing literature $[2,23,24]$, preterm births were subcategorized as (1) Very preterm (28-31 weeks of gestation), (2) Moderate preterm (32-34 weeks of gestation) and (3) Late preterm (35-36 weeks of gestation). Births at $\geq 37$ weeks were classified as term births. Following International Classification of Disease ( $10^{\text {th }}$ Revision) [25], all newborns with any sign of life at birth were recorded as live births.

Wealth index score [26] was constructed for each household by principal component analysis of basic housing construction materials (e.g. construction materials for the wall, roof, and floor) and household assets. We also estimated the straight line distance between nearest health facility and household by using location coordinates (longitude/latitude) for households and health facilities, collected by using global positioning system.

Percent distributions of term and preterm babies were computed by their care seeking status (from nonqualified and qualified providers or for non-care seekers). Crude 
associations between potential determinants for seeking care for preterm babies were modeled using binomial regression analysis with generalized linear model, by using log link (or a poisson model in case of convergence failure) [27-29]. To account for clustering, standard errors were adjusted using the generalized estimating equation approach with exchangeable correlation structure [30,31]. Factors associated with choice of providers were examined using multinomial logistic regression which is widely used for modeling polychotomous outcomes including health seeking behaviors [32-34]. "Hotdeck" method by cluster [35] was used to impute missing data for "birth preparedness status' and 'any ANC visit' variables. Analyses were conducted using STATA (version 12.1) [36].

\section{Ethical approval}

We received ethical approval from the Johns Hopkins Bloomberg School of Public Health Institutional Review Board and the Ethical Review Committee of the International Centre for Diarrhoeal Disease Research, Bangladesh.

\section{Results}

Between June 2007 and September 2009, we recorded 37,630 pregnancy outcomes and 35,908 live births within the study area. Of these, 27,460 mother-live born baby pairs (including 6,090 preterm babies) were analysed in this study (Figure 2). Most of the respondent women (89\%) were able to report their LMP date, and were included in the analyses.

\section{Determinants of seeking care (either curative or preventive) for preterm newborns Predisposing factors}

Maternal age, parental education and religion were not associated with care seeking for preterm newborns. Among all the reported preterm births, 46.7\% were female. Compared to male preterm babies, caregivers of female preterm newborns were $27 \%$ less likely to seek care (Relative Risk (RR): 0.73; 95\% Confidence Interval (CI): $0.66,0.80)$. There was no difference in care seeking for preterm babies born from multiple compared to singleton pregnancies (RR: 1.12; 95\% CI: 0.92, 1.35).

Among women who delivered preterm births, more than a quarter $(28.6 \%)$ had previously experienced the death of one of their children (any child born alive and died later). Table 1 shows a small, but statistically significant association was observed between likelihood of care-seeking for a preterm infant and history of a previous child death (RR: 0.96; 95\% CI: 0.93, 0.98).

Caregivers who had any ANC visit were $41 \%$ more likely to seek care for their preterm baby (RR: 1.41; 95\% CI: 1.25, 1.59). Likelihood of care-seeking was not significantly different among caregivers who had "Fully compliant” BNCP status (RR: 1.14; 95\% CI: 0.99, 1.30) compared to those who were "non-compliant".

\section{Enabling factors}

In Table 1, we found that higher socioeconomic status was associated with increased likelihood of care-seeking for preterm babies. Respondents in the richest group were $>1.5$ times more likely to seek care compared to the respondents in the poorest group [RR: 1.57; 95\% CI: $1.29,1.90]$. There was lower likelihood of care seeking for preterm babies from households further from facilities; compared to babies from households within $2 \mathrm{~km}$ of a health facility, preterm babies born $>2 \mathrm{~km}$ from a health facility were $25 \%$ less likely to seek care (RR: 0.75 ; 95\% CI: 0.66, 0.87).

\section{Need factors}

Among preterm babies, 17.5\% had reported symptoms of illness and $10.7 \%$ suffered birth asphyxia; signs of local infection were found among $4.5 \%$, and only a few $(1.8 \%)$ had signs of birth injury (Table 1). Care-seeking for preterm babies was $>2$-fold significantly higher among caregivers who had recognized symptoms of illness (RR: $2.14 ; 95 \%$ CI: 1.93, 2.38), or signs of local infections (RR: 2.53; 95\% CI: 2.23, 2.87). Preterm infants who suffered birth asphyxia (RR: $1.28 ; 95 \%$ CI: 1.12 , 1.45 ) or who had any birth injury (RR: $1.44 ; 95 \% \mathrm{CI}$ : $1.13,1.84$ ) were similarly found to have higher likelihood to be taken for care-seeking.

\section{Pattern of care seeking}

Analysing overall care seeking practice among all babies (term and preterm) revealed (in Table 2) that parents/ families of 21,644 (78.8\%) newborns sought 'no care', and care-seeking was significantly lower $(\mathrm{p}<0.01)$ among preterm newborns $(1,197 / 6,090 ; 19.7 \%)$ compared to babies born at term $(4,619 / 21,370 ; 21.6 \%)$. Among all careseekers, less than a third $(32.8 \%)$ of newborns sought care from qualified providers. The preferred health provider for neonatal care seeking was homeopathic practitioners (49.6\%) followed by qualified medical doctor $(21.8 \%)$. Provider preference was similar for term and for preterm infants, irrespective of preterm birth categories.

\section{Results from multinomial logistic regression analysis}

Estimated relative rate ratios (RRRs) for care seeking compared to not-seeking care among preterm newborns are presented in Table 3. Only father's educational status and sex of the child were significantly associated with care seeking from qualified (but not unqualified) providers as opposed to not seeking any care. Babies of fathers with five or more years of schooling compared to less than five years of schooling or no schooling were 


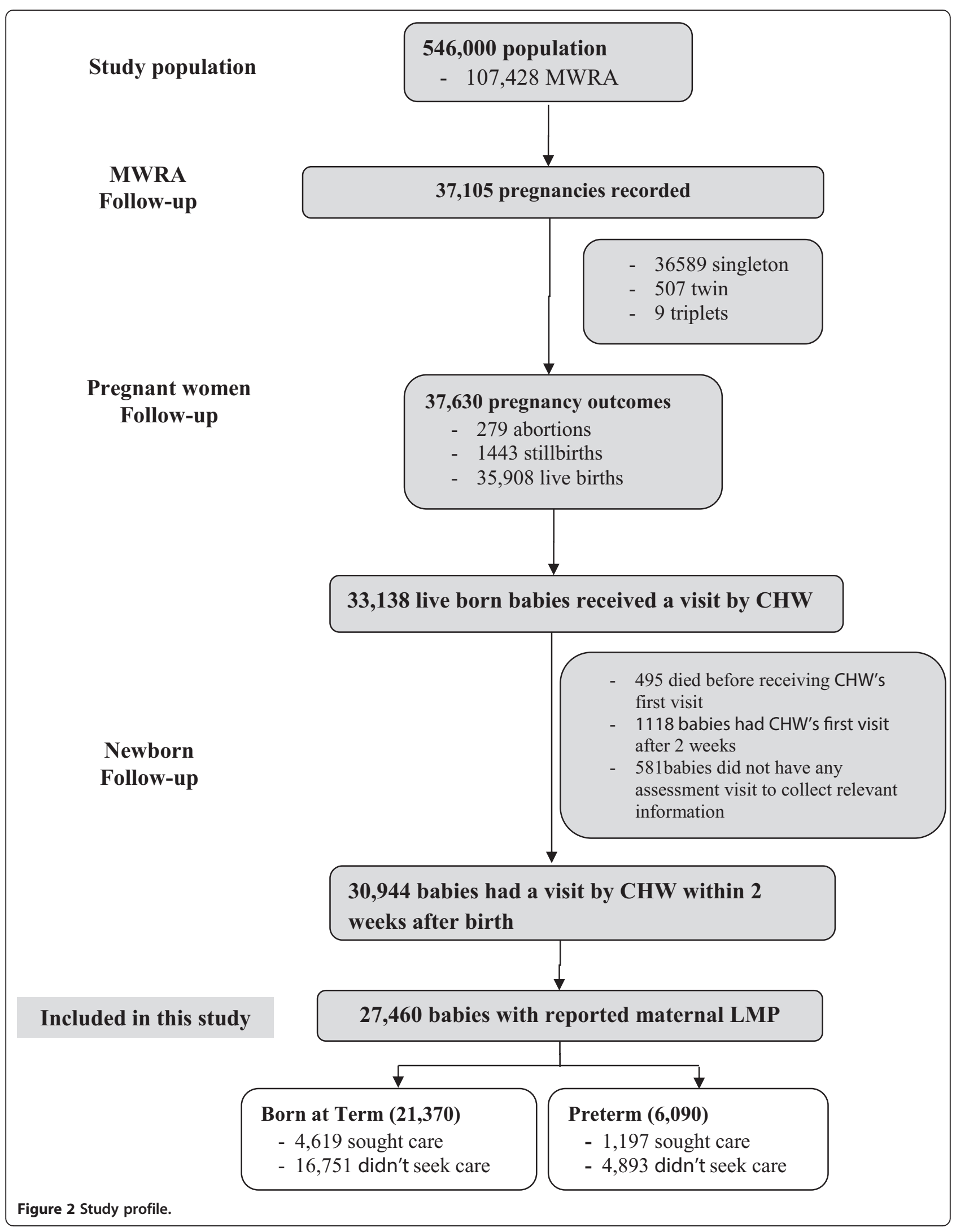


Table 1 Determinants of seeking care (either curative or preventive) for preterm newborns

\begin{tabular}{|c|c|c|}
\hline \multirow[t]{2}{*}{ Variables } & \multicolumn{2}{|c|}{ Newborns included in the study $N=27,460$} \\
\hline & Term newborns & Preterm newborns \\
\hline & $N=21,370$ & $N=6,090$ \\
\hline
\end{tabular}

$\mathrm{N}=6,090$

(\%)

(\%)

\section{Predisposing factors}

Mother's age

25-29 years $\quad 33.7$

30.1

33.5

30-34 years

20.3

22.0

35 years \& above

12.5

14.5

Mother's education

Below primary $\quad 47.5$

57.3

42.7

Primary and above 52.5

Father's education

Below primary $\quad 55.6$

64.3

Primary and above $\quad 44.4$

Religion

Islam

Others

4.6

95.7

4.3

Single/Multiple birth

Singleton $\quad 98.3$

Multiple birth $\quad 1.7$

95.4

4.6

History of child death

No $\quad 75.7$

71.4

28.6

Yes

Sex of the baby

Male

Female

48.7

Birth preparedness status

Not compliant $\quad 3.3$

Partially compliant $\quad 62.7$

Fully compliant $\quad 34.0$

Any ANC visit

$\begin{array}{lll}\text { No } & 40.3 & 49.8 \\ \text { Yes } & 59.7 & 50.2\end{array}$

Enabling factors

Wealth quintile

Lowest (Poorest) 18.6

Second lowest

19.0

23.4

23.5

Middle quintile

19.6

Second highest $\quad 20.4$

21.4

18.5

Highest (Richest) $\quad 22.3$
19.1

31.8

19.2

20.9

22.7

16.2

20.8

17.4

22.9

13.5

25.8
Preterm newborns who sought care

$\mathrm{N}=1,197$

Unadjusted risk ratio $(95 \% \mathrm{Cl})$

Adjusted $^{\epsilon}$ risk ratio $(95 \% \mathrm{Cl})$

n $\%$ (row)

$\begin{array}{lll}22.8 & \text { Ref } & \text { Ref } \\ 18.2 & 0.80(0.69,0.92)^{*} & 0.95(0.82,1.09) \\ 18.7 & 0.82(0.70,0.96)^{*} & 0.96(0.80,1.14) \\ 17.8 & 0.78(0.65,0.94)^{*} & 0.92(0.75,1.13) \\ & & \\ 17.5 & \text { Ref } & \text { Ref } \\ 22.6 & 1.29(1.15,1.45)^{*} & 1.08(0.96,1.22) \\ & & \\ 18.1 & \text { Ref } & \text { Ref } \\ 22.4 & 1.24(1.10,1.39)^{*} & 1.02(0.91,1.15) \\ & & \\ 19.8 & \text { Ref } & \text { Ref } \\ 17.6 & 0.89(0.66,1.19) & 1.03(0.79,1.34)\end{array}$

Ref Ref

$1.67(1.34,2.07) * 1.12(0.92,1.35)$

Ref Ref

$1.09(0.96,1.23) \quad 1.21(1.07,1.37)^{*}$

Ref Ref

$0.71(0.63,0.80)^{*} \quad 0.73(0.66,0.80)^{*}$

Ref Ref

$0.84(0.72,0.97)^{*} \quad 0.91(0.81,1.03)$

$1.10(0.94,1.29) \quad 1.14(0.99,1.30)$

Ref Ref

$1.92(1.70,2.16)^{*} \quad 1.41(1.25,1.59)^{*}$

13.7

Ref Ref

$1.26(1.05,1.52)^{*} \quad 1.18(1.00,1.39)$

$1.58(1.31,1.89)^{*} \quad 1.38(1.17,1.64)^{*}$

$1.60(1.33,1.93)^{*} \quad 1.34(1.13,1.60)^{*}$

$2.07(1.71,2.51)^{*} \quad 1.57(1.29,1.90)^{*}$ 
Table 1 Determinants of seeking care (either curative or preventive) for preterm newborns (Continued)

\begin{tabular}{|c|c|c|c|c|c|c|}
\hline \multicolumn{7}{|c|}{ Distance from health facility } \\
\hline Less than $2 \mathrm{Km}$ & 49.6 & 48.9 & 695 & 23.3 & Ref & Ref \\
\hline $2-2.99 \mathrm{Km}$ & 29.6 & 30.0 & 304 & 16.6 & $0.71(0.62,0.82)^{*}$ & $0.79(0.70,0.88)^{*}$ \\
\hline $3 \mathrm{Km}$ or more & 20.8 & 21.1 & 198 & 15.4 & $0.66(0.57,0.77) *$ & $0.75(0.66,0.87) *$ \\
\hline \multicolumn{7}{|l|}{ Need factors } \\
\hline \multicolumn{7}{|l|}{ Birth Asphyxia } \\
\hline No & 88.5 & 89.3 & 989 & 18.2 & Ref & Ref \\
\hline Yes & 11.5 & 10.7 & 208 & 32.0 & $1.76(1.51,2.04)^{*}$ & $1.28(1.12,1.45)^{*}$ \\
\hline \multicolumn{7}{|c|}{ Any signs of injury at birth } \\
\hline No & 98.0 & 98.2 & 1152 & 19.3 & Ref & Ref \\
\hline Yes & 2.0 & 1.8 & 45 & 40.9 & $2.12(1.58,2.86)^{*}$ & $1.44(1.13,1.84)^{*}$ \\
\hline \multicolumn{7}{|c|}{ Symptoms of illness } \\
\hline No & 84.1 & 82.5 & 767 & 15.3 & Ref & Ref \\
\hline Yes & 15.9 & 17.5 & 430 & 40.3 & $2.64(2.34,2.97)^{*}$ & $2.14(1.93,2.38)^{*}$ \\
\hline \multicolumn{7}{|c|}{ Signs of local infections } \\
\hline No & 94.9 & 95.5 & 1031 & 17.7 & Ref & Ref \\
\hline Yes & 5.1 & 4.5 & 166 & 60.6 & $3.42(2.90,4.03)^{*}$ & $2.53(2.23,2.87)^{*}$ \\
\hline
\end{tabular}

${ }^{*} \mathrm{p}<0.05$;

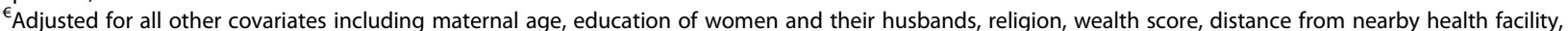
number of babies delivered, birth weight and sex of the newborn, signs/symptom of illness/infection, birth asphyxia, birth injury, history of child death, birth preparedness, ANC visit, $\pi$ immunization.

1.33 times (RRR: 1.33; 95\% CI:1.02, 1.74) more likely to seek care from qualified providers. The RRR of seeking care from both qualified and unqualified providers was significantly lower for female babies compared to male babies (RRR for qualified care: 0.52; 95\% CI: 0.41, 0.66; RRR for unqualified care: 0.68 ; $95 \%$ CI: $0.58,0.80$ ). Previous history of child death was associated with higher use of both of qualified and non-qualified care (RRR of qualified care: 1.52; 95\% CI: $1.12-2.05$; RRR of nonqualified care: 1.24; 95\% CI: 1.02 - 1.50). Complete birth preparedness (RRR: 1.24; 95\% CI: 1.09 - 1.68) and any ANC visit (RRR: 1.73; 95\% CI: $1.30-2.30$ ) increased the likelihood of care seeking from a qualified provider for preterm babies.

Household wealth quintile and distance from nearest health facility were significantly associated with care seeking, especially from qualified but also from nonqualified providers. All the need factors (except birth injury) in the model were significantly associated with using qualified and nonqualified care.

\section{Discussion}

Our findings confirm that parents and caregivers in rural Bangladesh are reluctant to seek care for preterm babies; among those who seek care, they prefer to consult with unqualified rather than qualified providers. Preterm neonates are especially vulnerable to temperature instability, feeding difficulties, low blood sugar, infections and breathing difficulties - conditions which pose a critical need for care seeking for preterm babies. The low rate of care seeking for preterm babies (19.6\%) in our study is consistent with findings from previous research in Bangladesh, Nepal, Pakistan and India [15].

Homeopathic practitioners are the preferred care providers for preterm infants in our study population. An earlier study conducted in same study area [20] reported similar parental preference for homeopathic care for their newborns over qualified and other non-qualified care providers. Homeopaths are mostly self-educated, but some possess recognized qualifications from government and/or private homeopathic colleges [37]. Both health care providers and parents often agree that very small babies or babies born too soon, irrespective of disease status, are 'high risk' (biomedical term) or 'vulnerable' (approximate translation of local terms). The difference lies in what is seen as appropriate treatment for vulnerable infants. Parents may perceive that biomedical treatments such as injections and antibiotics are too strong, and that vulnerable infants cannot withstand them. Parental preference for homeopathic providers is possibly because homeopathic medicine is thought to exert slow and gentle effects, which is perceived to be more acceptable than 'strong' modern medicines for a vulnerable baby.

Paternal education and sex of the newborn were significantly associated with care seeking from a qualified provider while mother's education was not. Although mothers take most health related decisions at home regarding diarrheal disease and immunizations [38], fathers 
Table 2 Distribution of newborns seeking curative and preventive care from different types of providers, by gestational age

\begin{tabular}{|c|c|c|c|c|c|}
\hline \multirow{4}{*}{$\begin{array}{l}\text { Type of } \\
\text { providers }\end{array}$} & \multirow{4}{*}{$\begin{array}{l}\text { Health care } \\
\text { Providers }\end{array}$} & \multicolumn{4}{|c|}{ Newborns for whom families/parents sought care health care ${ }^{*}$} \\
\hline & & \multirow{3}{*}{$\begin{array}{l}\text { Babies born at } \\
\text { Term ( }>37 \text { weeks) } \\
\text { and sought care } \\
\mathrm{N}=4,619\end{array}$} & \multicolumn{3}{|c|}{ Babies born preterm and sought care $(\mathrm{N}=1,197)$} \\
\hline & & & $\begin{array}{l}\text { Very preterm } \\
\text { (28-31 weeks) }\end{array}$ & $\begin{array}{l}\text { Moderate preterm } \\
\text { (32-34 weeks) }\end{array}$ & $\begin{array}{l}\text { Late preterm } \\
\text { (35-36 weeks) }\end{array}$ \\
\hline & & & $\mathrm{N}=135$ & $\mathrm{~N}=411$ & $N=651$ \\
\hline \multirow[t]{2}{*}{ Qualified } & $\begin{array}{l}\text { Doctor [Medical } \\
\left.\text { graduate }\left(\mathrm{MBBS}^{1}\right)\right]\end{array}$ & $1025(22.2)$ & $26(19.3)$ & $98(23.8)$ & $118(18.1)$ \\
\hline & $\begin{array}{l}\text { Nurse/Paramedic } \\
\left(\text { FWV/MA/SACMO }{ }^{1}\right)\end{array}$ & $514(11.1)$ & $18(13.3)$ & $43(10.5)$ & $67(10.3)$ \\
\hline \multirow[t]{5}{*}{ Non-Qualified } & HA/FWA ${ }^{1}$ & $66(1.4)$ & $2(1.5)$ & $6(1.5)$ & $17(2.6)$ \\
\hline & $\mathrm{CHW}^{1}$ & $99(2.1)$ & $6(4.4)$ & $10(2.4)$ & $22(3.4)$ \\
\hline & Homeopath & $2288(49.5)$ & $62(45.9)$ & $187(45.5)$ & $350(53.8)$ \\
\hline & Village Doctor & $387(8.4)$ & $12(8.9)$ & $40(9.7)$ & $46(7.1)$ \\
\hline & Others* & $240(5.2)$ & $9(6.7)$ & $27(6.6)$ & $31(4.8)$ \\
\hline
\end{tabular}

${ }^{¥}$ Figures are presented as numbers (percent); $x^{2}=6.66 ; p=0.084$.

*Ayurvedic, quack (Ojha, Kabiraj), Traditional Birth Attendant (TBA), Trained Traditional Birth Attendant (TTBA), herbal practitioner, Spiritual Leader/Imam (Muslim religious leader).

${ }^{1} M B B S=$ Bachelor of Medicine and Bachelor of Surgery; $F W V=$ Family Welfare Visitor; $S A C M O=$ Sub-Assistant Community Medical Officer; $M A=$ Medical Assistant; $H A=$ Health Assistant; FWA = Family Welfare Assistant; $C H W=$ Community Health Worker.

are more likely to take decisions for seeking care outside the home in rural Bangladeshi society [39]. Sex differential in care seeking has been reported in previous studies in South Asia [12,40]. Consistent with strong son preference in this region [41,42] and as reported in a study in rural India $[43,44]$, our study also revealed that female babies are less likely to be taken for qualified medical care compared to male babies.

We found that household wealth status and distance from the nearest health facility were significantly associated with care seeking from qualified providers in our study population, which is also consistent with previous reports [20]. Household economic status is an established factor associated with care seeking for children [12,40,45-50]. Distance from health facilities has also been an important barrier to health care access, including child health services, in other settings [50-52].

We found significant associations between positive health behaviours and antenatal practices (e.g., ANC visit, $\mathrm{BNCP}$ ) and care seeking for preterm babies from a qualified or unqualified provider. Moreover, similar to previously reported results [45,53], we also found a significant increase in the probability for care seeking for preterm newborns when signs of illnesses (asphyxia, birth injury, local infections including skin and eye infections and oral thrush) are recognized by parents or caregivers. These signs are visible, which may make family members more worried. Current evidence also shows that recognition of early danger signs of neonatal infections improves timely care seeking [54]. The strategy of study intervention delivery which included recognition of signs of illnesses among newborns by conducting assessments during postnatal home visits by trained CHWs, making referral and providing support to families for referral compliance also might explain such increased probability of care seeking for preterm newborns with signs of injury and infections. Our results reiterate an urgent need to educate parents/caregivers on recognition of risk factors and danger signs for mortality and morbidity for preterm babies. Although improved recognition of illness signs has been associated with increased care seeking in sick children [8,55-58], other socio-cultural factors are interlinked with decisions to seek care from a qualified provider $[6,20,59,60]$. For example, taking a sick infant outside the home is often perceived by the parents/caregivers as exposing the baby to increased risk of encountering malevolent spirits or the glare ("evil eye") of jealous neighbours, which is believed to be the source of illness $[12,20]$. In Sylhet, the concept of malevolent spirits is prevalent (locally called 'upri') and is believed to manifest in neonatal illnesses characterized by high fever, crying, not wanting to eat, black spots on the skin, unusual quietness and strange facial expressions. Similar effects are perceived as the outcome of a glare from a jealous neighbour (locally named as 'nazar') [20].

We enrolled a large number of mother-live born baby pairs and followed all live births through the neonatal period. Prospective design of this study eliminated the risk of selection as well as recall biases which are common in cross sectional and retrospective studies. Most of the known factors associated with care seeking practice were adjusted for in the analysis. However, a major limitation of the study was our reliance on LMP to determine gestational age. Common criticisms of the LMP 
Table 3 Multinomial logistic regression $\$$ analysis for care seeking (preventive or curative) for preterm newborns

\begin{tabular}{|c|c|c|c|c|}
\hline & \multicolumn{2}{|c|}{ Non-qualified care provider ${ }^{* *}$} & \multicolumn{2}{|l|}{ Qualified provider $^{*}$} \\
\hline & Relative Risk Ratio (RRR) & $95 \% \mathrm{Cl}$ & Relative Risk Ratio (RRR) & $95 \% \mathrm{Cl}$ \\
\hline \multicolumn{5}{|c|}{ Parental characteristics } \\
\hline \multicolumn{5}{|l|}{ Mother's age } \\
\hline$<25$ years & Ref & & Ref & \\
\hline $25-29$ years & 0.86 & $0.69-1.08$ & 0.93 & $0.66-1.31$ \\
\hline 30-34 years & 0.76 & $0.56-1.01$ & 1.51 & $1.01-2.27^{\circ}$ \\
\hline 35 years $\&$ above & 0.78 & $0.57-1.08$ & 1.11 & $0.67-1.82$ \\
\hline \multicolumn{5}{|l|}{ Mother's education } \\
\hline Below primary & Ref & & Ref & \\
\hline Primary and above & 1.14 & $0.94-1.39$ & 1.04 & $0.78-1.38$ \\
\hline \multicolumn{5}{|l|}{ Father's education } \\
\hline Below primary level & Ref & & Ref & \\
\hline Primary and above & 0.92 & $0.76-1.11$ & 1.33 & $1.02-1.74^{\circ}$ \\
\hline \multicolumn{5}{|l|}{ Religion } \\
\hline Islam & Ref & & Ref & \\
\hline Others & 1.00 & $0.66-1.51$ & 1.00 & $0.55-1.84$ \\
\hline
\end{tabular}

Household characteristics

Household wealth quintile

Lowest quintile (Poorest) Ref

Second lowest quintile $\quad 1.22$

Middle quintile $\quad 1.63$

Second highest quintile

Highest quintile (Richest)

Distance from health facility

Less than $2 \mathrm{Km} \quad$ Ref

$2-2.99 \mathrm{Km} \quad 0.78$

$3 \mathrm{Km}$ or more
0.78
0.82

$\begin{array}{ll} & \text { Ref } \\ 0.95-1.56 & 1.33 \\ 1.25-2.11^{\infty} & 1.53 \\ 1.09-1.90^{\infty} & 1.75 \\ 1.15-2.19^{\infty} & 2.84\end{array}$

Ref

0.36
$0.89-1.98$

$1.02-2.30^{\infty}$

$1.15-2.64^{\infty}$

$1.82-4.42^{\infty}$

$0.40-0.70^{\infty}$

$0.25-0.52^{\infty}$

Index pregnancy and previous obstetric related characteristics of the mother

Single/multiple birth

Singleton

Ref

Multiple birth

0.98

History of child death

No

Yes

Characteristics of the newborn

Sex of the baby

Male

Female

Birth Asphyxia

No

Yes

Any signs of injury at birth

No

Yes

\section{Ref}

1.24

Ref

0.68

Ref

1.45

Ref

1.39
$0.66-1.45$

$1.02-1.50^{\circ}$

Ref

1.52

Ref

0.52

Ref

1.69

Ref

2.97 $0.82-2.38$
$0.95-2.28$

$1.12-2.05^{\infty}$

$0.41-0.66^{\infty}$ $1.23-2.31^{\infty}$ 
Table 3 Multinomial logistic regression ${ }^{\$}$ analysis for care seeking (preventive or curative) for preterm newborns (Continued)

\begin{tabular}{|c|c|c|c|c|}
\hline \multicolumn{5}{|c|}{ Reported symptoms of illness } \\
\hline No & Ref & & Ref & \\
\hline Yes & 3.18 & $2.64-3.83^{\circ}$ & 3.50 & $2.71-4.53^{\infty}$ \\
\hline \multicolumn{5}{|c|}{ Signs of local infections } \\
\hline No & Ref & & Ref & \\
\hline Yes & 6.53 & $4.82-8.84^{\infty}$ & 5.06 & $3.35-7.65^{\circ}$ \\
\hline \multicolumn{5}{|c|}{ Health practices during antenatal period } \\
\hline \multicolumn{5}{|l|}{ Birth Preparedness } \\
\hline Not compliant & Ref & & Ref & \\
\hline Partially compliant & 0.90 & $0.73-1.10$ & 0.83 & $0.61-1.11$ \\
\hline Fully compliant & 1.17 & $1.04-1.47^{\infty}$ & 1.24 & $1.09-1.68^{\infty}$ \\
\hline \multicolumn{5}{|l|}{ Any ANC visit } \\
\hline No & Ref & & Ref & \\
\hline Yes & 1.54 & $1.28-1.86^{\circ}$ & 1.73 & $1.30-2.30^{\circ}$ \\
\hline
\end{tabular}

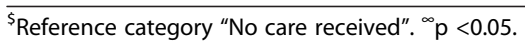

*Doctor (medical graduate), nurse, paramedic (Family Welfare Visitor, sub-assistant community medical officer) are considered as qualified provider.

${ }^{* *}$ All other providers.

method for gestational age determination include possible inaccuracy in recall, heaping on certain dates, and generalized assumption of "normal" menstrual cycle [61-63]. Given the need for clinical skills to determine gestational age by Dubowitz or Ballard methods and technical skills plus costs in using ultrasound, LMP remains the most feasible option in many rural, low resource settings such as ours. A related concern is the potential threat of having selection bias due to exclusion of women who could not report their LMP date. We examined for any differential in the characteristics of women whom we excluded, and found nothing significant. By restricting analyses to newborns visited by a CHW within two weeks after the birth, we may have potentially introduced survival bias; for example by excluding a baby who died before receiving a CHW visit ( $\mathrm{n}=495 ; 1.8 \%$ of 27,460$)$.

\section{Conclusions}

Our study results yielded the following recommendations to improve health care seeking for preterm babies in similar settings: 1) Involve community-preferred health care providers, even if they are unqualified (i.e.- not qualified in terms of western medicine practice; for example: homeopathic practitioners), to facilitate community-based health education and awareness raising programs; consider training them to recognize signs of illness and to refer sick newborns to qualified providers/facilities; and 2) Integrate postnatal care seeking messages (for both mother and baby) into antenatal counselling. Simultaneously, community-based health counselling and behaviour change communication strategies might have the potential to improve parental recognition of illness leading to early health care seeking for newborns, specifically preterm babies, and thus possibly will be critical for achieving success in community-based maternal and newborn health programs in low-income countries. Finally, we recommend further studies on communitylevel care seeking practices for preterm babies which would help in planning programs to reduce morbidity and mortality risks for babies who are 'Born Too Soon'.

\section{Additional files}

Additional file 1: Basic Prenatal Maternal and Newborn Care Package [web-only].

Additional file 2: Operational Definitions** [web-only].

\section{Competing interests}

The authors declare that they have no competing interests.

\section{Authors' contributions}

$\mathrm{RS}, \mathrm{AHB}$ and LCM were primarily responsible for conceptualizing and designing this study. LCM, AHB, SEA and GLD were responsible for protocol development and study design of the main study (Chlorhexidine trial). AHB and SEA were the principal investigators of the Projahnmo Chlorhexidine study. RS, IM, SMR, GLD, LCM were co-investigators of the main study. RS conducted the literature review, data analyses and drafted the manuscript. RRT, DM and NB supported literature review, data management and analyses. All authors have contributed in interpretation of results and provided critical intellectual input in editing and revising the manuscript; and finally approved the manuscript for submission.

\section{Authors' information}

ProjAHNMo stands for Project for Advancing Health of Newborn and Mothers.

\section{Acknowledgements}

The study was conducted by the Projahnmo study group in Bangladesh. Projahnmo is a partnership of the ICDDR,B; the Bangladesh government's 
Ministry of Health and Family Welfare; Bangladeshi nongovernmental organizations, including Shimantik, Save the Children-US, Dhaka Shishu Hospital and the Institute of Child and Mother Health; and the Johns Hopkins Bloomberg School of Public Health. We thank the members of the Projahnmo study team, including Projahnmo field and data management staff who worked tirelessly, and our colleagues at the Bangladesh Ministry of Health and Family Welfare at the sub-district, district and national levels for their valuable support. We are also thankful to many individuals in Sylhet for their generous support and timely effort to conduct this study successfully. Funding for the Projahnmo Project was provided by the United States Agency for International Development, Office of Health, Infectious Diseases, and Nutrition, Global Health Bureau and the Dhaka Mission through the Global Research Activity Cooperative Agreement (GHS-A-00-03-00019-00), and the Saving Newborn Lives initiative of Save the Children through a grant from the Bill and Melinda Gates Foundation.

Rashed Shah was supported through a Fogarty Training Grant (Grant \# D43TW7587) during the period of data analyses and manuscript writing

\section{Author details}

${ }^{1}$ Department of International Health, International Center for Maternal and Newborn Health (ICMNH), Johns Hopkins Bloomberg School of Public Health, Baltimore, Maryland, USA. ${ }^{2}$ Department of Health and Nutrition, Save the Children-USA, Washington, DC, USA. ${ }^{3}$ Global Development Division, Bill and Melinda Gates Foundation, Seattle, WA, USA. International Centre for Diarrheal Disease Research, Bangladesh (icddr,b), Mohakhali, Dhaka, Bangladesh. ${ }^{5}$ Ma-Moni Project, MCHIP/Save the Children, Bangladesh Country office, Dhaka, Bangladesh.

Received: 15 January 2014 Accepted: 15 September 2014 Published: 22 September 2014

\section{References}

1. World Health Organization: UNICEF: Low birth weight: country, regional and global estimates. Geneva: World Health Organization; 2004.

2. World Health Organization, March of Dimes, PMNCH, Children: St: Born too soon: the global action report on preterm birth. In The global action report on preterm birth. Edited by Howson C, Kinney M, Lawn J. Geneva: WHO; 2012.

3. Anne CC L, Joanne K, Hannah B, Simon C, Naoko K, Vogel JP, Linda A, Baqui AH, Bhutta ZA, Caulfield LE, Parul C, Clarke SE, Majid E, Wafaie F, Rogelio G, Lieven H, Simon K, Patrick K, John L, Tanya M, Mario M, Aroonsri M, Mullany LC, James N, Marie-Louise N, Jyh Kae N, David O, Dominique R, Rosen HE, Ayesha $\mathrm{S}$, et al: National and regional estimates of term and preterm babies born small for gestational age in 138 low-income and middle-income countries in 2010. Lancet Global Health 2013, 1(1):e26-e36.

4. Joanne K, Anne CC L, Naoko K, Lawn JE, Simon C, Hannah B, Majid E, Bhutta ZA, Tanya M, Willey BA, Linda A, Fernando B, Baqui AH, Parul C, Wafaie F, Rogelio G, Jean H, Lieven H, Patrick K, Aroonsri M, Mullany LC, Richard N, Jyh Kae N, David O, Dominique R, Ayesha S, Christentze S, Silveira MF, James T, Anjana $\mathrm{V}$, et al: Mortality risk in preterm and small-forgestational-age infants in low-income and middle-income countries: a pooled country analysis. Lancet 2013, 382(9890):417-425.

5. Herbert HK, Lee ACC, Chandran A, Rudan I, Baqui AH: Care seeking for neonatal illness in low- and middle-income countries: a systematic review. PLoS Med 2012, 9(3):e1001183. doi:10.1371/journal.pmed.1001183.

6. Awasthi S, Srivastava N, Pant S: Symptom-specific care-seeking behavior for sick neonates among urban poor in Lucknow, Northern India. J Perinatol 2008, 28(Suppl 2):S69-S75.

7. Awasthi S, Verma T, Agarwal M: Danger signs of neonatal illnesses: perceptions of caregivers and health workers in North India. Bull World Health Organ 2006, 84(10):819-826.

8. Hill Z, Kendall C, Arthur P, Kirkwood B, Adjei E: Recognizing childhood illnesses and their traditional explanations: exploring options for care-seeking interventions in the context of the IMCI strategy in rural Ghana. Trop Med Int Health 2003, 8(7):668-676.

9. Bazzano AN, Kirkwood BR, Agyemang CT, Agyai SO, Adongo PB: Beyond symptom recognition: care-seeking for ill newborns in rural Ghana. Trop Med Int Health 2008, 13:123-128.

10. Makinen $M$, Waters $H$, Rauch M, Almagambetova N, Bitran R, Gilson L, McIntyre D, Pannarunothai S, Prieto AL, Ubilla G: Inequalities in health care use and expenditures: empirical data from eight developing countries and countries in transition. Bull World Health Organ 2000, 78(1):55-65

11. Mercer A, Haseen F, Huq NL, Uddin N, Khan MH, Larson CP: Risk factors for neonatal mortality in rural areas of Bangladesh served by a large NGO programme. Health Policy Plan 2006, 21(6):432-443.

12. Ahmed S, Sobhan F, Islam A, Barkat eK: Neonatal morbidity and care-seeking behaviour in rural Bangladesh. J Trop Pediatr 2001, 47(2):98-105.

13. Baqui AH, Arifeen SE, Williams E, Ahmed S, Mannan I, Rahman S, Begum N, Seraji H, Winch P, Santosham M, Black RE, Darmstadt GL, for the Projahnmo 1 Study Group: Effectiveness of home-based management of newborn infections by community health workers in rural Bangaldesh. Pediatr Infect Dis J 2009, 28(4):304-310.

14. Bhutta ZA, Zaidi AK, Thaver D, Humayun Q, Ali S, Darmstadt GL: Management of newborn infections in primary care settings: a review of the evidence and implications for policy? Pediatr Infect Dis J 2009, 28(1):S22-S30.

15. Syed U, Khadka N, Wall S: Care seeking practices in South Asia: using formative research to design program interventions to save newborn lives. J Perinatol 2008, 28(Suppl. 2):S9-S13.

16. Hill Z, Manu A, Tawiah-Agyemang C, Gyan T, Turner K, Weobong B, Ten Asbroek A, Kirkwood B: How did formative research inform the development of a home-based neonatal care intervention in rural Ghana \& quest. J Perinatol 2008, 28:S38-S45.

17. Khadduri R, Marsh D, Rasmussen B, Bari A, Nazir R, Darmstadt G: Household knowledge and practices of newborn and maternal health in Haripur district, Pakistan. J Perinatol 2007, 28(3):182-187.

18. Andersen $\mathrm{R}$, Newman JF: Societal and individual determinants of medical care utilization in the United States. Milbank Mem Fund Q Health Soc 1973, 51(1):95-124.

19. Amin R, Shah NM, Becker S: Socioeconomic factors differentiating maternal and child health-seeking behavior in rural Bangladesh: a cross-sectional analysis. Intl J Equity Health 2010, 9(1):9.

20. Winch PJ, Alam MA, Akther A, Afroz D, Ali NA, Ellis AA, Baqui AH, Darmstadt GL, Arifeen SE, Seraji MH: Local understandings of vulnerability and protection during the neonatal period in Sylhet District, Bangladesh: a qualitative study. Lancet 2005, 366(9484):478-485.

21. Shams El A, Mullany LC, Rasheduzzaman S, Ishtiaq M, Rahman SM, Talukder MRR, Nazma B, Ahmed A-K, Darmstadt GL, Mathuram S, Black RE, Baqui AH: The effect of cord cleansing with chlorhexidine on neonatal mortality in rural Bangladesh: a community-based, cluster-randomised trial. Lancet 2012, 379(9820):1022-1028.

22. WHO: Recommended definitions, terminology and format for statistical tables related to the perinatal period and use of a new certificate for cause of perinatal deaths. Acta Obstet Gynecol Scand 1977, 56:247-253.

23. Blencowe H, Cousens S, Oestergaard MZ, Chou D, Moller A-B, Narwal R, Adler A, Vera Garcia C, Rohde S, Say L: National, regional, and worldwide estimates of preterm birth rates in the year 2010 with time trends since 1990 for selected countries: a systematic analysis and implications. Lancet 2012, 379(9832):2162-2172.

24. Engle WA: A recommendation for the definition of "Late Preterm" (Near-Term) and the birth weight-gestational age classification system. Semin Perinatol 2006, 30(1):2-7.

25. WHO: International Classification of Diseases and Related Health Problems10th Revision. World Health Organization; 2004.

26. Filmer D, Pritchett LH: Estimating wealth effects without expenditure data-or tears: an application to educational enrollment in states of India. Demography 2001, 38:115-132.

27. McNutt $L A, W u C, X u e X$, Hafner JP: Estimating the relative risk in cohort studies and clinical trials of common outcomes. Am J Epidemiol 2003, 157(10):940-943.

28. Skov T, Deddens J, Petersen MR, Endahl L: Prevalence proportion ratios: estimation and hypothesis testing. Int J Epidemiol 1998, 27(1):91-95.

29. Wacholder S: Binomial regression in GLIM: estimating risk ratios and risk differences. Am J Epidemiol 1986, 123(1):174-184.

30. Liang KY, Zeger SL: Longitudinal data analysis using generalized linear models. Biometrika 1986, 73(1):13-22.

31. Zeger SL, Liang KY: Longitudinal data analysis for discrete and continuous outcomes. Biometrics 1986, 42(1):121-130.

32. McFadden D: Econometric analysis of qualitative response models. In Handbook of Econometrics. 2nd edition. Edited by Griliches Z, Intriligator M. Amsterdam, North-Holland: 1984:1395-1457. 
33. Theil $\mathrm{H}$ : A multinomial extension of the linear logit model. Int/ Economic Rev 1969, 10(3):251-259.

34. Jowett M, Deolalikar A, Martinsson P: Health insurance and treatment seeking behaviour: evidence from a low-income country. Health Econ 2004, 13(9):845-857.

35. Levy PS: Missing Data Estimation,"Hot Deck" and "Cold Deck". In Encyclopedia of Biostatistics. 2005.

36. StataCorp: Stata Statistical Software: Release 12. College Station, TX: StataCorp LP; 2011

37. Ahmed SM, Hossain MA, Chowdhury MR: Informal sector providers in Bangladesh: how equipped are they to provide rational health care? Health Policy Plan 2009, 24:467-478.

38. Ahmed S, Parveen SD, Islam A: Infant feeding practices in rural Bangladesh: policy implications. J Trop Pediatr 1999, 45(1):37-41.

39. Darmstadt GL, Syed U, Patel Z, Kabir N: Review of domiciliary newborn-care practices in Bangladesh. J Health Popul Nutr 2006, 24(4):380-393.

40. Najnin N, Bennett CM, Luby SP: Inequalities in care-seeking for febrile illness of under-five children in urban Dhaka, Bangladesh. $J$ Health Popul Nutr 2011, 29(5):523-531.

41. Chowdhury MK, Bairagi R: Son preference and fertility in Bangladesh. Popula Development Rev 1990, 16(4):749-757.

42. Clark S: Son preference and sex composition of children: evidence from India. Demography 2000, 37(1):95-108.

43. Willis JR, Kumar V, Mohanty S, Singh P, Singh V, Baqui AH, Awasthi S, Singh $J V$, Santosham M, Darmstadt GL: Gender differences in perception and care-seeking for illness of newborns in rural Uttar Pradesh, India. $J$ Health Popul Nutr 2009, 27(1):62-71.

44. Willis JR, Kumar V, Mohanty S, Kumar A, Singh JV, Ahuja RC, Misra RP, Singh P, Singh V, Baqui AH, Sidhu S, Santosham M, Darmstadt GL, Saksham Study Group: Utilization and perceptions of neonatal healthcare providers in rural Uttar Pradesh, India. Int J Qual Health Care 2011, 23(4):487-494.

45. Taffa N, Chepngeno G: Determinants of health care seeking for childhood illnesses in Nairobi slums. Trop Med Int Health 2005, 10(3):240-245.

46. Pokhrel S, Sauerborn R: Household decision-making on child health care in developing countries: the case of Nepal. Health Policy Plan 2004, 19(4):218-233.

47. Goldman N, Pebley AR: Childhood immunization and pregnancy-related services in Guatemala. Health Transit Rev 1994, 4(1):29-44.

48. Pillai RK, Williams SV, Glick HA, Polsky D, Berlin JA, Lowe RA: Factors affecting decisions to seek treatment for sick children in Kerala, India. Soc Sci Med 2003, 57(5):783-790.

49. Thind A: Health service use by children in rural Bihar. J Trop Pediatr 2004 50(3):137-142

50. Sasaki S, Fujino Y, Igarashi K, Tanabe N, Muleya CM, Suzuki H: Access to a health facility and care-seeking for danger signs in children: before and after a community-based intervention in Lusaka, Zambia. Trop Med Int Health 2010, 15(3):312-320.

51. Hjortsberg C, Mwikisa C: Cost of access to health services in Zambia. Health Policy Plan 2002, 17(1):71-77.

52. Buor D: Analysing the primacy of distance in the utilization of health services in the Ahafo-Ano South district. Ghana. Int J Health Plann Manage 2003, 18(4):293-311.

53. Sreeramareddy C, Shankar R, Sreekumaran B, Subba S, Joshi $H$ Ramachandran U: Care seeking behaviour for childhood illness-a questionnaire survey in western Nepal. BMC Int Health Hum Rights 2006, 6(7). doi:10.1186/1472-698X-6-7.

54. Choi Y, Arifeen SE, Mannan I, Rahman SM, Bari S, Darmstadt GL, Black RE, Baqui AH: Can mothers recognize neonatal illness correctly? comparison of maternal report and assessment by community health workers in rural Bangladesh. Trop Med Int Health 2010, 15(6):743-753.

55. D'Souza R: Care-seeking behavior. Clin Infect Dis 1999, 28(2):234

56. Goldman N, Heuveline P: Health-seeking behaviour for child illness in Guatemala. Trop Med Int Health 2000, 5(2):145-155.

57. Goldman N, Pebley A, Gragnolati M: Choices about treatment for ARI and diarrhea in rural Guatemala. Soc Sci Med 2002, 55(10):1693-1712.

58. Yoder P, Hornik R: Symptoms and perceived severity of illness as predictive of treatment for diarrhea in six Asian and African sites. Soc Sci Med 1996, 43(4):429-439.

59. Baqui AH, Rahman M, Zaman K, El Arifeen S, Chowdhury HR, Begum N, Bhattacharya G, Chotani RA, Yunus M, Santosham M, Black RE: A population based study of hospital admission incidence rate and bacterial aetiology of acute lower respiratory in children less than five years in Bangladesh $J$ Health Popul Nutr 2007, 25(2):179-188.

60. Kaushal M, Aggarwal R, Singal A, Shukla H, Kapoor S, Paul V: Breastfeeding practices and health-seeking behavior for neonatal sickness in a rural community. J Trop Pediatr 2005, 51(6):366-376.

61. Lynch $C D$, Zhang J: The research implications of the selection of a gestational age estimation method. Paediatr Perinat Epidemiol 2007, 21(s2):86-96.

62. Wegienka G, Baird DD: A comparison of recalled date of last menstrual period with prospectively recorded dates. J Women's Health (2002) 2005 14(3):248-252.

63. Savitz DA, Terry JW Jr, Dole N, Thorp JM Jr, Siega-Riz AM, Herring AH: Comparison of pregnancy dating by last menstrual period, ultrasound scanning, and their combination. Am J Obstet Gynecol 2002, 187(6):1660-1666

doi:10.1186/1472-6963-14-417

Cite this article as: Shah et al:: Determinants and pattern of care seeking for preterm newborns in a rural Bangladeshi cohort. BMC Health Services Research 2014 14:417.

\section{Submit your next manuscript to BioMed Central and take full advantage of:}

- Convenient online submission

- Thorough peer review

- No space constraints or color figure charges

- Immediate publication on acceptance

- Inclusion in PubMed, CAS, Scopus and Google Scholar

- Research which is freely available for redistribution

Submit your manuscript at www.biomedcentral.com/submit
C Biomed Central 